\title{
Museisamlingarnas sociomateriella dynamik
}

Lotten Gustafsson Reinius*, Eva Silvén* \& Fredrik SvanberG*

Title: The sociomaterial dynamics of museum collections

Abstract: "The sociomaterial dynamics of museum collections" is an overarching research idea connecting three separate projects, with the aim of creating new knowledge about the roles of collections and collecting in the shaping of culture and society. The program includes three Swedish national museums that have been decisive in defining Sweden, Swedishness and the surrounding world - the Nordiska Museet (Swedish cultural history) the National Historical Museum (history, archaeology) and the Museum of Ethnography (the third/fourth world). In one study each, two ethnologists and one archaeologist will focus on objects and issues that have in some way been pointed out as problematic but which also seem to have a strong ability to define identity, social relations and create both conflict and reconciliation: collections from indigenous peoples, human remains and repatriation. The program includes three separate and ongoing projects, financed by Riksbankens Jubileumsfond and The Swedish Research Council. The projects are connected by a shared interest in the dynamic interplay between material practices and social processes of change. This will be analyzed with an emphasis on turning points in collecting, classification, display and storage, such as the relocation of objects between and from the museums mentioned.

Key words: Mobility, networks, ritualization, collections, repatriation, minorities, indigenous peoples, human remains, identity politics, materiality.

Museisamlingarnas sociomateriella dynamik är en övergripande forskningsidé som förenar tre separata projekt med målet att generera ny kunskap om samlandets och samlingarnas roller i skapandet av samhälle och kultur. Programmet innefattar tre nationella museer som spelat centrala roller för att definiera såväl Sve- rige och det svenska som omvärlden: Nordiska museet (svensk kulturhistoria), Historiska museet (svensk historia och arkeologi) samt Etnografiska museet (tredje/fjärde världen). I varsin studie analyserar två etnologer och en arkeolog föremål och företeelser som på något vis uppfattats som problematiska men som 
98 också varit betydelsefulla för att skapa identiteter, relationer, konflikt och försoning, nämligen samlingar från urfolk, mänskliga kvarlevor samt repatrieringsprocesser. Programmet utgår från tre befintliga större projekt, finansierade av Riksbankens Jubileumsfond och Vetenskapsrådet: Konstruktionen av ett samiskt kulturarv: Ernst Manker och Nordiska museet, Huvudjägarna, Museum anatomicum och samlandets sociala dynamik samt Försoningsritualer $i$ det postsekulära museet.

\section{FORSKNINGSFRÅGOR OCH SYFTE}

Svenska museer förvaltar många miljoner föremål från olika tider och platser i världen. Samlingarna utgör basen för ett omfattande utställningskomplex och en stor pedagogisk verksamhet. De bildar dessutom infrastruktur och en central resurs för en stor del av den humanistiska forskningen. Efter att länge ha betraktats som oproblematiska delar av ett materiellt och nationellt kulturarv måste samlingarna och samlingsverksamheten mot bakgrund av de senaste årens kunskapsutveckling inom humaniora förstås och utforskas på nya sätt, med uppmärksamhet på tingens sociala roller och museisamlingarnas samhällsskapande funktioner. Samtidigt ställer både den nationella utvecklingen av ett mångfaldssamhälle och kulturarvets globalisering krav på en radikalt förnyad etik för de svenska museernas hantering av sina förvärv och kunskapen om dem.

Samlingsverksamheten kännetecknas inte bara av en fysisk materialitet och förvaltningen av denna utan även av kulturella processer som skapar och förändrar samlandet. Genom urval vid insamling, i skapandet av klassifikationssystem samt i utställningar blir samlingarna i sin tur kultur- och samhällsskapande. Deras symboliska laddning, förvaring och för- flyttning spelar stor roll i olika gruppers identitetsprocesser och inbördes relationer. Det är denna växelverkan mellan socialt och materiellt som vi kallar "museisamlingarnas sociomateriella dynamik". Programmet syftar till att genom utforskandet av denna dynamik skapa ny kunskap om museernas och samlandets kulturella och samhälleliga roller. Vi utgår från att skiftande politiska och moraliska konjunkturer har sina motsvarigheter i brytpunkter inom museipraktiken. Därför har vi valt att fokusera hanteringen av föremål och samlingar som museerna själva, vid något historiskt tillfälle, pekar ut som problematiska eller anomaliska.

Som empiriska studieobjekt har vi valt samlingar och samlingspraktiker på tre centralmuseer som, både sammantagna och vart och ett för sig, har varit formerande för svenska självoch omvärldsbilder: Nordiska museet, Statens historiska museum och Etnografiska museet. Dessa museers historia, samlingar och nutida praktik har särskild samhällelig relevans i dagens Sverige och är sammanflätade på ett sätt som ger ett rikt underlag för vår analys. En metodisk länk är det komparativa perspektiv som möjliggörs av att museerna förs samman i ett program där de blir möjliga att betrakta som relaterade och konstruerade helheter inom ett större nationellt kulturarvsfält. I stället för att utgå från gränserna mellan historia, kulturhistoria och etnografi tillhör det forskningsuppgiften att se hur dessa gränser har skapats och befästs med hjälp av samlingarna.

Inom programmet behandlas ovan nämnda gemensamma problematik genom varsitt projekt: Konstruktionen av ett samiskt kulturarv: Nomadiserande samlingar, Huvudjägarna, Museum anatomicum och samlandets sociala dynamik samt Försoningsritualer $i$ det postsekulära museet. Det första projektet, Konstruktionen av 
ett samiskt kulturarv: Nomadiserande samlingar är en undersökning av formandet av de tre museernas samiska samlingar i relation till folkgruppens förändrade identitet och samhälleliga status. Huvudjägarna, Museum anatomicum och samlandets sociala dynamik innefattar en analys av en samling mänskliga kvarlevor utifrån dess karaktär av sociomateriellt nätverk. Försoningsritualer $i$ det postsekulära museet, slutligen, undersöker hur nationella själv- och omvärldsbilder artikuleras och hanteras i repatrieringsprocesser som genomförts eller genomförs vid de nämnda museerna. Även om de tre studierna har skilda fokus och tyngdpunkt på olika aspekter ingår de $\mathrm{i}$ ett gemensamt kunskapsbygge och samtal om programmets analytiska och teoretiska tema.

\section{FORSKNINGSSAMMANHANG OCH TEORETISKA UTGÅNGSPUNKTER}

Programmet knyter an till flera aktuella problemområden inom det kulturhistoriska och kulturvetenskapliga fältet. Bland annat finns möjlighet att bidra till pågående diskussioner om kulturarv och identitetspolitik, det materiellas kulturella betydelser samt det framväxande mediehistoriska fältet. I första hand hämtas impulser från den så kallade nya museologin, en mångvetenskaplig inriktning som vuxit fram sedan det tidiga 1990-talet och bland annat genererat forskning om museernas meningsproduktion och samhällsroll i olika historiska, politiska och sociala kontexter (Karp \& Lavine 1991; Bennett 1995, 2004; Pearce 1995; Hooper-Greenhill 2000; Knell 2004; Karp m.fl. 2006; Knell, MacLeod \& Watson 2007).

Av särskild betydelse är studier som diskuterat de politiska, ideologiska och estetiska dimensionerna av samlande och föremålens rol- ler i skilda betydelsesystem (Pearce 1989, 2004; Stewart 1993; Bourdieu 1984). En internationell diskussion om museers samlingar i förhållande till minoritetsgrupper och urfolk har hämtat näring ur den nya museologin, också som utgångspunkt för nya arbetssätt och samarbetsformer (t.ex. Smith 1999; Fforde 2004; Brown \& Peers 2006; Smith 2006; Robson, Treadwell \& Gosden 2006; Gabriel \& Dahl 2008). Till den politiska dimensionen hör också undersökningar av hur museer bidrar till att konstituera nationer och nationaliteter (Kaplan 1994; Boswell \& Evans 1999; Knell m.fl. 2011).

I en aktuell översikt (Svanberg 2009) konstateras att den nya museologin haft ett markant inflytande i Sverige, men hittills främst på det teoretiska planet. Det finns också arbeten som berör de tre museernas samlingar och/eller delar vissa frågeställningar med programmet (t.ex. Beckman 1999; Östberg 2002, 2010; Houltz 2003; Mordhorst 2003; Ljungström 2004; Hillström 2006; Nilsson Stutz 2009; Hallgren 2010; Baglo 2011; Muñoz 2011).

Programmet tar ett tidigare oprövat grepp över flera museer och har ambitionen att injicera det museologiska fältet med teori- och metodutveckling. Som nämnts är en utgångspunkt att de tre museernas samlingsverksamhet kan betraktas som en sammanflätad process. Samlingarna utgör ett sociomateriellt nätverk där föremål, människor, medier och institutioner samverkar i att upprätthålla (eller förändra) kollektiva identiteter, kategorier och minnen. För detta övergripande ramverk kommer vi att förena perspektiv från aktörsnätverksteori (Latour 1987, 1998, 2005; Law \& Hassard 1999; Law \& Mol 2002) med Foucaults klassiska tankar om genealogiska brytpunkter, kunskapsteknologier och mikromakt- 
LotTen Gustafsson Reinius, Eva Silvén \& Fredrik SVAnberg

100

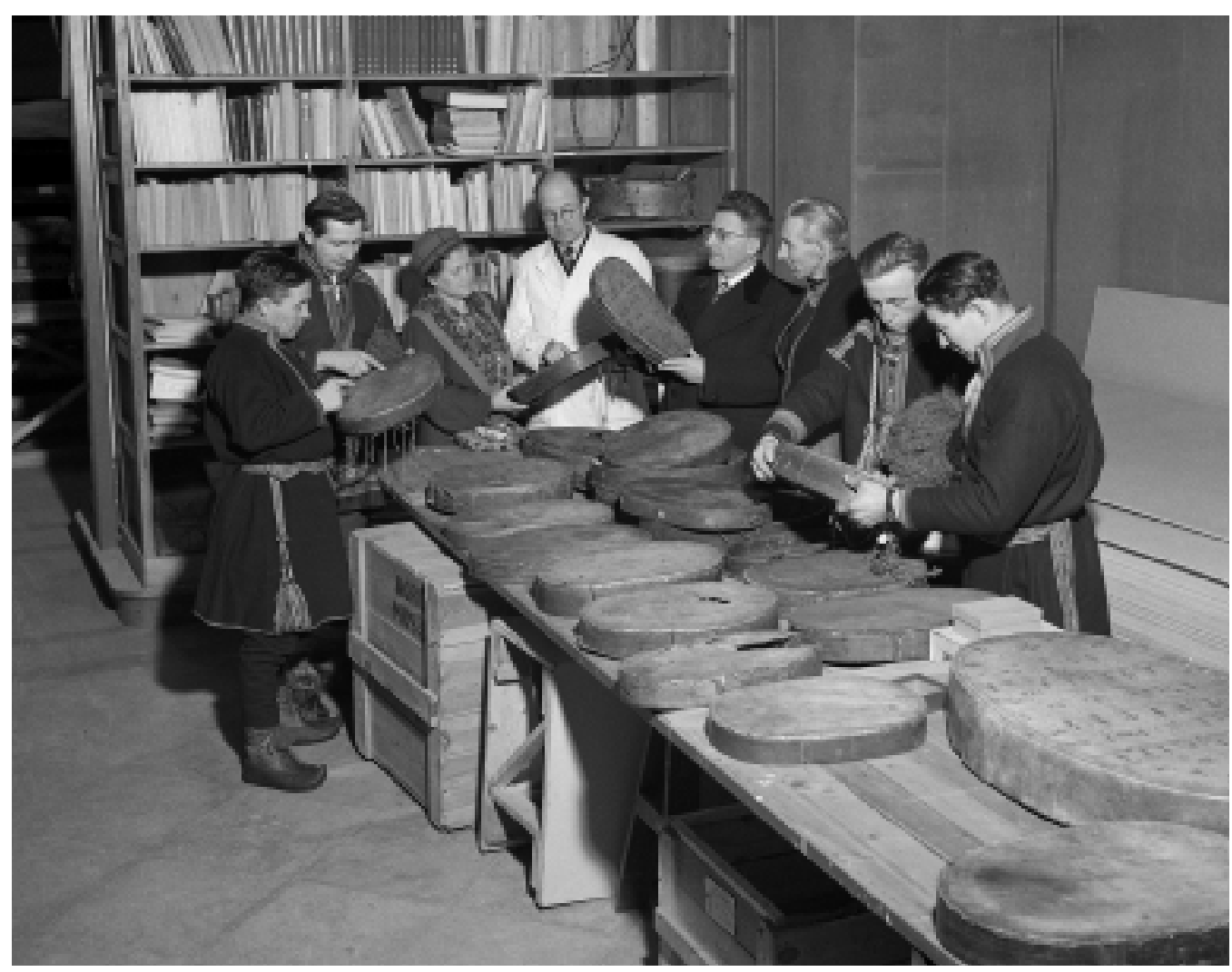

Fig. 1. En samisk delegation, utsedd av regeringen, studerar trummor vid ett besök i Nordiska museet 1945. Frän vänster: Mattias Kuoljok, John Utsi, Anna Gustafsson, Ernst Manker (museets intendent), Gustaf Park, Petrus Gustafsson, Isak Parffa och Nils Erik Kuoljok. Foto: Nordiska museet.

analys (1970, 1972, 1980). För diskussionen om museiföremålens roller hämtas också inspiration från aktuella antropologiska diskussioner om det socialas materialitet (Miller 2005; Henare, Holbraad \& Wastell 2006). Tingens sinnliga och affektiva betydelser i museipraktiker kommer också att diskuteras, med inspiration av de fenomenologiska perspektiv som vuxit fram inom sinnenas antropologi (Howes 2005; Edwards, Gosden \& Phillips 2006). För analysen av mobilitet i samlingsverksam- heten kommer vi bland annat att använda oss av Creswells (2006) problematisering av rörlighet och stillastående i moderniteten.

\section{Eva SilvÉN: KONSTRUKTIONEN AV ETT SAMISKT KULTURARV: NOMADISERANDE SAMLINGAR}

Till frågan om museisamlingars sociala dynamik hör förflyttningar av såväl enskilda objekt som hela kategorier av föremål inom, utom 
och mellan museer. En hypotes är att den sortens rörelser är fruktbara ingångar till studier av identitetsskapande och kulturell förändring. Utifrån programmets syfte har de tre museernas samiska samlingar valts för en sådan analys; merparten är föremål av kulturhistorisk natur men här finns också mänskliga kvarlevor. Samerna är och var en del av det svenska men samtidigt något annorlunda, vilket gestaltas av vilka föremål som har förvärvats, hur de har benämnts och klassificerats samt till vilka museer de har förts. I den processen liksom i fortsatta förflyttningar mellan museerna, magasinen och utställningarna är de fysiska objekten signifikanta aktörer i de sociala nätverk som museerna, universiteten och det samiska samhället utgör.

Nordiska museet började förvärva föremål med samisk härkomst från starten 1873. I 1919 års statliga gränsdragning mellan ett antal museer beslöts att "lapparnas kultur" skulle tillhöra Nordiska museets ansvarsområde, och under flera decennier gjordes omfördelningar mellan Historiska och Nordiska museet i syfte att renodla samlingarna. Pådrivande var Ernst Manker, intendent vid Nordiska museet (Silvén 2010, 2011). Etnografiska museet hade också en samling samiska föremål, vilket vittnar om att samerna inte självklart betraktades som en del av den svenska befolkningen. 1989, när Ájtte, Svenskt fjäll- och samemuseum i Jokkmokk, bildades deponerades Etnografiska museets samiska samlingar där - som en akt av repatriering och ett uttryck för en ny maktordning.

Studien syftar till att belysa museernas gemensamma roll för föreställningar om samisk identitet. Metodiskt kommer frågan att ställas om hur de samiska samlingarna byggts upp och förändrats, kategoriserats och klassificerats samt visats i utställningar, med fokus på rörelser och förskjutningar inom och mellan museerna (Silvén 2008, 2011, 2012). Museet är inte någon stilla slutstation för objekt som tagits ur cirkulation. Föremålen har där en fortsatt historia - i magasin, utställningar, hos konservatorer, forskare och andra brukare. Här kommer ovan nämnda teorier om materialitet och aktörsnätverk samt begrepp som "tingens kulturella biografier" (Kopytoff 1986) och "following the object" (Czarniawska 2007) att tas i bruk för att analysera värdehierarkier, estetiska konjunkturer och maktrelationer.

En aspekt av museiföremålens samhällsskapande funktion är att studera hur bilden av samerna har formats genom samlingarnas kategorier och rubriker (Stewart 1993; Svanberg 2009; Rogan 2010; Muñoz 2012). Genom de begreppsliga kategoriernas makt över tankar och föreställningar (Foucault 1972) har den plats som samerna fixerades vid i museernas taxonomier sannolikt kommit att styra förväntningarna. Vad kan man tänkas hitta i en samling "samiska" föremål och vad inte? Hur blev föremålen och människorna "samiska"? I ett mer övergripande perspektiv kommer dessa frågor att förbindas med såväl samernas som de tre museernas förändrade samhällsposition över tid.

FREDRIK SVANBERG: HuVUdJÄGARNA, MUSEUM ANATOMICUM OCH SAMLANDETS SOCIALA DYNAMIK

Studien sätter fokus på Uppsala universitets gamla anatomiska samling av mänskliga kvarlevor som ett exempel på ett idag problematiskt kulturarv som finns representerat i alla tre museernas historia. År 1996 påträffades en större samling skelettdelar paketerade i lådor i Uppsala universitets förrådslokaler. Samlingen består av en mängd mänskliga kranier, övrigt 
102 mänskligt benmaterial, gipsbyster av människohuvuden samt ett antal dödsmasker i gips. Samlingen har tillhört anatomiska institutionen i Uppsala, den har insamlats runt förra sekelskiftet och magasinerats under 1950-talet. Drygt 1000 kranier samt gipsbyster och dödsmasker ur samlingen skänktes 1997 till Historiska museet men har 2011 återgått till Museum Gustavianum i Uppsala.

Ofullständiga uppgifter om samlingen har kunnat identifieras i katalogverket "Museum Anatomicum Upsaliense". Uppgifter i katalogerna visar att kvarlevorna i samlingen till största delen kommer från arkeologiska utgrävningar men många även från dissekerade människor. Dessutom finns kvarlevor från Lappland (samiska), Egypten, Grekland, Grönland, Indonesien, Italien, Mikronesien, Hawaii, Norge, Peru, Polen, Kolahalvön, Spanien, Sri Lanka, Sudan och möjligen flera länder.

Kompletterande fakta visar att materialet sammanbragts med en rad olika motiv, bland annat i en målmedveten vetenskaplig huvudjakt i syfte att skapa källmaterial för den statliga svenska rasforskning som i Uppsala först bedrevs vid anatomiska institutionen, senare vid Statens institut för rasbiologi. Denna forskning är i idéhistorisk mening väl känd genom arbeten där de skriftliga källmaterialen analyserats (Broberg 1995; Broberg \& Tydén 2005), medan dess detaljer, olika specifika sammanhang och relationer till olika institutioner och personer (jfr Ljungström 2004) återstår att undersöka.

Här finns ett en gång legitimt och aktivt insamlat forskningsmaterial som under lång tid tystats ner och gömts undan men som idag återfătt sin status som källmaterial, fast nu för museologisk forskning. Inledningsvis kommer samlingens tillkomst och användning över tid att undersökas, det vill säga insamlandets ka- raktär, motiv och sammanhang samt hur materialet använts i forskning och undervisning. Delstudien närmar sig samlingen utifrån antagandet att denna kan betraktas som ett nätverk av relationer mellan föremål, institutioner och människor. Avsikten är både att analysera vad samlingen representerar i olika kontexter och hur det nämnda nätverket kan förstås, i ett aktörsnätverksteoretiskt perspektiv (Law \& Hassard 1999; Law \& Mol 2002; Latour 2005). Vilket slags relationer är inbäddade i skapandet och förvaltningen av denna samling? Vilken över tid föränderlig social dynamik kännetecknar den? Vilka samhälleliga konsekvenser får den här sortens samlande och samlingsförvaltning?

Studierna av denna samling ska kopplas till andra likartade material vid Historiska museet (inklusive depositioner från Nordiska museet) samt Etnografiska museet (se bl.a. Svanberg u.u.) med avsikt att utvidga nätverksundersökningen och diskutera hur rasforskningens materiella kulturarv hanteras i en nutida kontext vid och mellan de tre museerna.

\section{LotTEn Gustafsson Reinius:}

FÖRSONINGSRITUALER I DET POSTSEKULÄRA MUSEET

Många museer brukas idag av olika aktörer som offentliga och rituella arenor för moraliska, politiska och sociala problemlösningar. Det ceremoniella återlämnandet av totempålen från Etnografiska museet våren 2006 är bara ett exempel på detta aktuella och internationella fenomen. De så kallade repatrieringarna kan förstås som en variant av en framväxande genre av postkoloniala försoningsritualer: välregisserade och mediebevakade offentliga iscensättningar, där politiska och religiösa ledare, genom att tillfälligt och rituellt göra sig 
till bärare av historisk skuld, gör anspråk på att finna vägar till försoning för brott och konflikter i det förflutna.

Genom jämförande fallstudier av återföranden som hanterats av de tre museerna analyserar detta projekt samlingarnas roller i sökandet efter en förnyad och globaliserad kulturarvsetik och kommunikativa former för denna. Ambitionen är att, genom valda nedslag, diskutera de betydelser föremål, platser och människor ges i rituella markeringar i samband med återlämnande och återkomst. I möjligaste mån kommer detta att studeras genom deltagande observation. Ett par sådana fältarbeten har redan genomförts vid Etnografiska museets ceremoniella återlämnanden, av aboriginska kranier (2004) och av totempålen (2006). För fördjupad kunskap om den administrativa och rituella hanteringen kommer också intervjuer, intern dokumentation och pressmaterial att ingå i forskningsmaterialet.

Den typ av återlämnanden som hittills fått mest uppmärksamhet involverar etnografiska museer och urfolk. Genom att blickfältet omfattar tre museer blir det möjligt att jämföra fall som ger uttryck också för andra problematiker, exempelvis Nordiska museets hanterande av förfrågningar från nordiska grannländer samt till Historiska museet ställda krav från regionala museer och Svenska kyrkan. Om vilka värden etableras moraliskt konsensus och var mobiliseras istället motstånd och förhandlingar? Finns det en hierarki mellan olika anspråk, andligheter och etniciteter? Vilka rituella roller kan intas och av vem? Anspråken och deras hanterande tycks teckna konturerna av ett framväxande moraliskt landskap, där en kulturell förhandling om ansvar, skuld, identitet, helighet, ägande och plats ges rituell form.

Valet av metodisk ingång bygger på en syn på ritualer som symboltäta och kommunikati- va arenor, med särskilda förutsättningar att ge rum åt polyfona förhandlingar om existentiella och samhälleliga konflikter (bl.a. Turner 1969; Connerton 1989). Genom uppmärksammandet av växelspelet mellan materiellt och socialt, som också genomsyrar programmet som helhet, ansluter studien också till det växande vetenskapliga intresset för tingens agens (Latour 1998; Law 1994) och det socialas materialitet (Miller 2005; Henare, Holbraad \& Wastell 2006). Om man, med Latour (1998:19-21), tänker sig att museiföremålen ingått i ett nätverk där deras materialitetet bidragit till att hållbarhet åt maktrelationer och kulturella gränsdragningar (jfr Gustafsson Reinius 2008: 40), kan man också fråga sig vad av det som rubbas när de blir mobila igen och bryts loss ur den tidigare helheten. Öppnar museernas nya ritualer några "svarta lådor" eller rör det sig i själva verket om ett nytt, och lika effektivt, förseglande av andra ordningar och roller (jfr Gustafsson Reinius 2010, 2012)?

\section{PROgRAMmets BETYDELSE FÖR FORSKNINGSFÄLTET}

Programmets viktigaste vetenskapliga bidrag till pågående forskning är det metodiska greppet över flera museer och det sociomateriella perspektivet på museisamlandet. Studiet av de tre museernas interaktion kommer att fånga in generella tendenser samtidigt som det frilägger mönster i form av en intressant svensk särart. Sverige deltog exempelvis inte som nation i 1800-talets stora koloniseringsprocesser. Ändå har det under senare år allt mer kommit att uppmärksammas hur det svenska samhället inom det egna landets gränser kan sägas vara arvtagare till ett kolonialt tänkande och agerande i förhållande till samerna, samtidigt som de utomeuropeiska museisamlingarna 
vittnar om individers och gruppers delaktighet i det koloniala projektet. Också den på sin tid framstående svenska rasforskningen brukar nämnas i dessa sammanhang.

De tre forskarna kommer att arbeta inom programmet 2010-2014, med varierande insatser över tid. Utöver de publikationer och presentationer som varje enskilt projekt resulterar i skapar dialogen och samarbetet i programmet också gemensamma möjligheter för metod- och teoriutveckling som kan spridas internationellt och nationellt i tal och skrift.

Forskningsprogrammet placerar sig i den internationellt och nationellt framväxande mångvetenskapliga kulturarvsforskningen. Forskargruppen har etablerat samverkan med Eunamus (European National Museums: Identity Politics, the Uses of the Past and the European Citizen), ett större europeiskt program för forskning om nationalism och museer, under ledning av Peter Aronsson vid Linköpings universitet (www.eunamus.eu; Aronsson 2011). Vid Acsis (Advanced Cultural Studies Institute of Sweden, Linköpings universitet) internationella konferens i juni 2011 arrangerade programmet och Eunamus tillsammans en större session om aktuell museologi (Fredriksson 2011). I januari 2012 presenterades de tre projekten och de gemensamma ingångarna i Bryssel vid Eunamuskonferensen National Museums and the Negotiation of Difficult Pasts. Även fortsättningsvis räknar vi med att medverka gemensamt i olika former av forskarsamarbeten, teoretiskt och metodiskt utvecklingsarbete och debatt.

Genom programmet möjliggörs också en reflektion över de specifika förutsättningar, tillgångar och problem som det innebär att bedriva museologi inifrån. Vilka särskilda möjligheter öppnar sig för forskningen när den växer fram i dialog med museets inre arbete och publika praktik? Vari ligger svårigheterna? Genom att programmet ställer frågor som berör en pågående offentlig diskussion, där en global mångfaldsetik står i fokus, kommer vi också att kunna bidra med infallsvinklar och perspektiv av relevans för samhället i stort.

\section{REFERENSER}

Aronsson, P.: Identity Politics and Uses of the Past with European National Museums. Nordisk Museologi 2011:1.

Baglo, C.: På ville veger. Levende utstillinger av samer i Europa og Amerika. Tromsø 2011.

Beckman, J.: Naturens palats. Nybyggnad, vetenskap och utställning vid Naturhistoriska riksmuseet 1866-1925. Stockholm 1999.

Bennett, T.: The Birth of the Museum. History, Theory, Politics. London 1995.

- Pasts Beyond Memory. Evolution, Museums, Colonialism. London 2004.

Boswell, D. \& Evans, J. (red.): Representing the Nation: A Reader. Histories, Heritage and Museums. London 1999.

Bourdieu, P.: Distinction. A Social Critique of the Judgment of Taste. London 1984.

Broberg, G.: Statlig rasforskning. En historik över Rasbiologiska institutet. Lund 1995.

Broberg, G. \& Tydén, M.: Oönskade i folkhemmet. Rashygien och sterilisering i Sverige. Stockholm 2005 (2. uppl.).

Brown, A.K. \& Peers, L.: Pictures Bring us Messages. Photographs and Histories from the Kainai Nation. Toronto 2006.

Connerton, P.: How Societies Remember. Cambridge 1989.

Creswell, T.: On the Move. Mobility in the Modern Western World. New York 2006.

Czarniawska, B.: Shadowing and Other Techniques for Doing Fieldwork in Modern Societies. Malmö 2007. 
Edwards, E., Gosden, C. \& Phillips, R.B. (red.): Sensible Objects. Colonialism, Museums and Material Culture. Oxford 2006.

Fforde, C.: Collecting the Dead. Archaeology and the Reburial Issue. London 2004.

Foucault, M.: The Order of Things. London 1970.

- Vetandets arkeologi. Stockholm 1972.

- Power/Knowledge. Selected Interviews and Other Writings 1972-1977. Red. C. Gordon. Brighton 1980.

Fredriksson, M. (red.): Current Issues in European Cultural Studies, June 15-17, Norrköping, Sweden, 2011 (ACSIS). Conference Proceedings. Linköping 2011. (www.ep.liu.se/ecp_home/ index. en.aspx?issue $=062)$

Gabriel, M. \& Dahl, J. (red.): Utimut. Past Heritage - Future Partnerships. Discussions on Repatriation in the 21st Century. Köpenhamn 2008.

Gustafsson Reinius, L.: Innanför branddörren. Etnografiska samlingar som medier och materialitet. I Jülich, S., Lundell, P. \& Snickars, P. (red.). Mediernas kulturhistoria. Stockholm 2008. - Ordna. I Cronqvist, M. (red.). Allt som tänkas kan. 29 ingångar till vetenskapens villkor.

Stockholm 2010.

- Där karbunkelstenarna en gång satt. Om hur föremål går förlorade och återvinns. I Drakos G., Engman J. \& Ronström O. (red). Folkloristikens aktuella utmaningar. Visby 2012.

Hallgren, C.: Mänskliga kvarlevor. Ett problematiskt kulturarv. Stockholm 2010.

Henare, A., Holbraad, M. \& Wastell, S. (red.): Thinking through Things. Theorising Artefacts Ethnographically. London 2006.

Hillström, M.: Ansvaret för kulturarvet. Studier i det kulturhistoriska museiväsendets formering med särskild inriktning på Nordiska museets etablering 1872-1919. Linköping 2006.

Hooper-Greenhill, E.: Museums and the Interpretation of Visual Culture. London 2000.

Houltz, A.: Teknikens tempel. Modernitet och industriarv på Göteborgsutställningen 1923.

Howes, D.: Introduction. I Empire of the Senses. The Sensual Culture Reader. Oxford 2005.

Kaplan, F.E.S. (red.): Museums and the Making of "Ourselves". The Role of Objects in National Identity. London 1994.

Karp, I. m.fl. (red.): Museum Frictions. Public Cultures/Global Transformations. Durham, NC 2006.

Karp, I. \& Lavine, S.D. (red.): Exhibiting Cultures. The Poetics and Politics of Museum Display. Washington 1991.

Knell, S.J (red.): Museums and the Future of Collecting. Aldershot 2004 (2. uppl.).

Knell, S.J., MacLeod, S. \& Watson, S. (red.): Museum Revolutions. How Museums Change and are Changed. London 2007.

Knell, S. J. m.fl. (red.): National Museums. New Studies from Around the World. London 2011.

Kopytoff, I.: The Cultural Biography of Things. Commoditization as Process. I Appadurai, A. (red.). The Social Life of Things. Commodities in Cultural Perspective. Cambridge, UK 1986.

Latour, B.: Science in Action. Cambridge, Mass. 1987. - Artefaktens återkomst. Ett möte mellan organisationsteori och tingens sociologi. Göteborg 1998. - Reassembling the Social. An Introduction to Actor-Network-Theory. Oxford 2005.

Law, J.: Organizing Modernity. Oxford 1994.

Law, J. \& Hassard, J.: Actor Network Theory - and after. Blackwell 1999.

Law, J. \& Mol, A. (red.): Complexities. Social Studies of Knowledge Practices. Durham 2002.

Ljungström, O.: Oscariansk antropologi. Etnografi, forhistoria och rasforskning under sent 1800-tal. Hedemora 2004.

Miller, D. (red.): Materiality. Durham, NC 2005.

Mordhorst, C.: Genstandsfortallinger. Fra Museum Wormianum til de moderne museer. Roskilde 2003. Muñoz, A.: From Curiosa to World Culture. The 
History of the Latin American Collections at the Museum of World Culture in Sweden. Göteborg 2011.

Nilsson Stutz, L. Archeology, Identity, and the Right to Culture. Anthropological Perspectives on Repatriation. Current Swedish Archaeology 2007/08:15/16, 2009.

Pearce, S. (red.): Museum Studies in Material Culture. Leicester 1989.

- On Collecting. An Investigation into Collection in the European Tradition. London 1995.

- Collections and Collecting. I Knell, S. (red.). Museums and the Future of Collecting. Aldershot 2004 (2. uppl).

Robson, E., Treadwell, L. \& Gosden, C. (red.): Who Owns Objects? The Ethics and Politics of Collecting Cultural Artefacts. Oxford 2006.

Rogan, B.: Tingenes orden. Klassifikasjon, samling, museum. I Rogan, B. \& Bugge Amundsen, A. (red.). Samling og museum. Kapitler av museenes historie, praksis og ideologi. Oslo 2010.

Silvén, E.: Staging the Sámi - Narrative and Display at the Nordiska Museet in Stockholm. I

Aronsson, P. \& Nyblom, A. (red.). Comparing. National Museums, Territories, Nation-Building and Change. Linköping 2008.

- Ernst Manker 1893-1972. I Hellspong, M. \& Skott, F. (red.). Svenska etnologer och folklorister. Uppsala 2010.

- Nomadising Sami Collections. I Fredriksson, M. (red.). Current Issues in European Cultural Studies, June 15-17, Norrköping, Sweden, 2011. Conference Proceedings. Linköping 2011.

- Contested Sami Heritage: Drums and Sieidis on the Move. I Poulot, D., Bodenstein, F. \& Lanzarote Guiral, J.M. (red.). National Museums and Difficult Pasts. Conference Proceedings from Eunamus, Brussels, January 26-27, 2012. Linköping 2012.

Smith, L.: Uses of Heritage. London 2006.

Smith, L.T.: Decolonizing Methodologies. Research and Indigenous Peoples. London 1999.
Stewart, S.: On Longing. Narratives of the Miniature, the Gigantic, the Souvenir, the Collection. Durham 1993.

Svanberg, F.: Museer och samlande. Stockholm 2009. - Historien, som den samlats. I Grundberg, M., Hegardt, J., Nordström, P. \& Svanberg, F. Fyra röster om ett museum. Stockholm u.u.

Turner, V.: The Ritual Process. Structure and AntiStructure. Ithaca, NY 1969.

Östberg, W. (red.): Med världen i kappsäcken. Samlingarnas väg till Etnografiska museet. Stockholm 2002.

- Vem tillhör föremålen? Konstskatter frän kungariket Benin i Etnografiska museets samlingar. Stockholm 2010.

*Lotten Gustafsson Reinius, docent $i$ etnologi

Adress: Etnografiska museet

Box 27140, SE-102 52 Stockholm, Sverige

E-mail: lotten.gustafsson@varldskulturmuseerna.se

*Eva Silvén, fil. dr i etnologi

Adress: Nordiska museet

Box 27820 SE-115 93 Stockholm, Sverige

E-mail: eva.silven@nordiskamuseet.se

*Fredrik Svanberg, docent $i$ arkeologi

Adress: Historiska museet

Box 5428, SE-11484 Stockholm, Sverige

E-mail: fredrik.svanberg@historiska.se 